\title{
Avaliação do desempenho de frangos de corte alimentados com rações contendo probiótico e diferentes níveis de nucleotídeos
}

\author{
Performance evaluation of broilers fed diets containing probiotic and different nucleotides levels
}

\author{
João Batista Canevari BRUNO ${ }^{1}$; Ricardo de ALBUQUERQUE ${ }^{1}$; Leonila Ester RASPANTINI ${ }^{2}$; Estela \\ KOBASHIGAWA; ${ }^{3}$ Messias Alves da TRINDADE NETO ${ }^{1}$; Lucio Francelino ARAÚJO $^{3}$; Ramalho José \\ Barbosa RODRIGUEIRO ${ }^{4}$
}
${ }^{1}$ Departamento de Nutrição e Produção Animal da Faculdade de Medicina Veterinária e Zootecnia da Universidade de São Paulo, Pirassununga - SP, Brasil
${ }^{2}$ Centro de Pesquisa em Toxicologia Veterinária (CEPTOX) do Departamento de Patologia da Faculdade de Medicina Veterinária e Zootecnia da Universidade de São Paulo, Pirassununga - SP, Brasil
${ }^{3}$ Departamento de Zootecnia da Faculdade de Zootecnia e Engenharia de Alimentos da Universidade de São Paulo, Pirassununga - SP, Brasil
${ }^{4}$ Gerente Técnico da CJ do Brasil, São Paulo - SP, Brasil

\begin{abstract}
Resumo
O objetivo deste trabalho foi avaliar o desempenho de frangos de corte alimentados com ração contendo um probiótico comercial e diferentes níveis de nucleotídeos. Foram utilizados 1050 pintos de 01 dia, machos da linhagem Ross 308 totalizando trinta e cinco aves por boxe, em um delineamento inteiramente casualizado com cinco repetições por tratamento. As aves foram criadas até 42 dias de idade, e receberam as rações experimentais a base de milho e farelo de soja contendo 6 níveis de nucleotídeos (0; 100; 200; 300; 400 e 500 gramas por tonelada de ração). Os nucleotídeos foram utilizados na fase inicial ( 1 a 21 dias) e fase de crescimento (22 a 35 dias). Durante a fase final (36 a 42 dias) os nucleotídeos foram removidos da ração. Houve melhora linear no desempenho dos frangos no período de 1 a 21 dias, indicando que, quanto maior o nível de nucleotídeos na dieta, maior o peso corporal das aves. A conversão alimentar também melhorou linearmente nesse período à medida que aumentou o nível de nucleotídeos na ração. O peso no período de 35 dias, também teve um comportamento linear, semelhante ao período de 1 a 21 dias, indicando que, o nível de nucleotídeos na ração melhorou o desempenho. A concentração plasmática de acido úrico demonstrou efeito quadrático no período de 1 a 21 dias, indicando 231,59 gramas de nucleotídeos por tonelada de ração, como o melhor, em níveis mínimos de ácido úrico, por outro lado, no período de 35 dias de idade, estimou-se o nível de 208,99 g de nucleotídeos por tonelada de ração; como o melhor em níveis mínimos de ácido úrico no sangue. No período final (35 a 42 dias) e período total (1 a 42 dias de idade) não foi possível o observar efeito dos contrastes testados neste trabalho.
\end{abstract}

Palavras-chave: Aditivos. Alimentação. Desempenho. Bases Pirimídicas. Bases Púricas.

\begin{abstract}
The objective of this study was to evaluate the performance of broilers fed diets containing a commercial probiotic and different levels of nucleotides. One thousand and fifty chicks 1-d male were reared in a randomized experimental design with five replications of each treatment, distributed in 30 experimental boxes with 35 birds each. The diets contained corn and soybean meal with six different nucleotídes levels $(0 ; 100 ; 200 ; 300 ; 400$ and 500 grams for ton of ration), and the different nucleotides levels were used in the initial phase ( 1 to 21 days of age) and growth phase ( 22 to 35 days of age). During the final phase ( 36 to 42 days) nucleotides were removed from the feed. There was improvement on broilers performance in the period from 1 to 21 days of age, demonstrating proportionality between nucleotides level in the diet of broilers and body weight of the birds. Feed conversion at 21 days of age was directly proportional to nucleotides level in the diet. Body weight at 35 days of age, also had a linear behavior, similar to the period from 1 to 21 days, indicating that the nucleotides level in the feed improved the performance. Plasma uric acid concentration demonstrated quadratic effect at 21 days of age, showing that 231,59 grams of nucleotides for ton of feed had the minimum level of plasma uric acid concentration. At 35 days of age, concentration of 208,99g of nucleotides for ton of feed had the minimum level of plasma uric acid concentration. No effects were observed in the final period ( 35 to 42 days of age) and total period ( 1 to 42 days of age) it was not demonstrated effect of the contrasts tested in this study.
\end{abstract}

Keywords: Additive. Feeding. Performance. Nucleic Acid Base. Pyrimidine and Purine.

Correspondência para:

Ricardo de Albuquerque

Departamento de Nutrição e Produção Animal (VNP)

Avenida Duque de Caxias - norte, 225, Campus da USP, Pirassununga SP
CEP: $13635-900$

e-mail: ricalbuq@usp.br

Recebido: 16/06/2009

Aprovado: 29/02/2012

Braz. J. Vet. Res. Anim. Sci., São Paulo, v. 49, n. 1, p. 5-11, 2012 


\section{Introdução}

A busca constante de melhoria de produtividade aliada ao melhoramento genético das linhagens de frangos de corte, cada dia mais exigentes, depende de uma nutrição equilibrada. Essas necessidades energéticas e protéicas são atendidas especialmente com dietas compostas de milho e farelo de soja. A utilização de proteínas de origem animal é uma prática que está sendo discutida pelos nutricionistas, principalmente após o aparecimento de doenças como a BSE (Encefalopatia Espongiforme Bovina), e presença de Salmonella ssp (TIBBETTS ${ }^{1}$ ). A preocupação também é com o uso contínuo de antibióticos que pode levar ao desenvolvimento e disseminação de populações bacterianas resistentes, e que essa resistência possa ser transferida aos microorganismos patogênicos, transformando-se num risco tanto para saúde humana quanto animal ${ }^{2}$. Diante dessas evidências, medidas estão sendo adotadas para utilização destes produtos nas rações de aves, em praticamente todas as partes do mundo, observando uma demanda crescente por produtos isentos de resíduos químicos e ingredientes de origem animal ${ }^{3}$.

Os prováveis substitutos aos antibióticos devem manter a ação benéfica de promover o crescimento dos animais e contornar o efeito indesejável que é a resistência bacteriana. Um grupo de aditivos que pode ser utilizado como alternativa aos promotores de crescimento são os probióticos. Várias pesquisas comprovam a eficiência destes produtos em promover a exclusão competitiva em nível intestinal das aves, melhorando o desempenho das mesmas.

Os nucleotídeos são aditivos alternativos de grande valia para obtenção da produtividade aliada à qualidade dos produtos finais na criação moderna de frangos de corte, estes produtos são nutrientes considerados condicionalmente essenciais que participam da divisão e do crescimento celular, modulando o sistema imunológico e estabelecendo a integridade do intestino (aumento do tamanho e da densidade dos vilos intestinais), melhorando assim a saúde, a prevenção e recuperação imediata dos distúrbios intestinais ${ }^{4}$. Segundo estes autores, os nucleotídeos, quando fornecidos na dieta dos animais, aumentam a atividade das enzimas digestivas presentes no intestino.

Os nucleotídeos são tradicionalmente utilizados na alimentação humana, principalmente em dietas para recém-nascidos, e atuam no desenvolvimento do trato gastrintestinal, no funcionamento do sistema imune e na manutenção da flora intestinal. Uauy, Quan e $\mathrm{Gil}^{5}$ observaram que a suplementação de $0,8 \%$ de nucleotídeos promoveu o crescimento e a maturação intestinal em ratos jovens, aumentando a altura das vilosidades e a profundidade das criptas e de DNA no intestino. Diante do exposto, o objetivo deste trabalho foi verificar o efeito de diferentes níveis de nucleotídeos em frangos de corte alimentados com rações contendo um probiótico.

\section{Material e Método}

O experimento foi conduzido em Junho e Julho de 2008, na Faculdade de Medicina Veterinária e Zootecnia da Universidade de São Paulo, Campus Pirassununga.

A dieta experimental era isonutritiva à base de milho e farelo de soja, cuja formulação obedecia aos níveis nutricionais rotineiramente empregados na criação comercial de frangos de corte. A dieta inicial (1-21 dias), possuía $2950 \mathrm{kcal} / \mathrm{kg}$ de energia metabolizável (EM), 22,5\% de proteína bruta (PB), 0,35\% de metionina, $0,71 \%$ de metionina + cistina, $0,95 \%$ de cálcio e $0,45 \%$ de fósforo disponível. A dieta de crescimento (22-35 dias) possuía $3100 \mathrm{kcal} / \mathrm{kg}$ de EM, 20,0\% de $\mathrm{PB}, 0,32 \%$ de metionina, $0,65 \%$ de metionina + cistina, $0,95 \%$ de cálcio e $0,35 \%$ de fósforo disponível. A dieta da fase final (35-42 dias) possuía $3150 \mathrm{kcal} /$ kg de EM, $18,0 \%$ de PB, $0,30 \%$ de metionina, 0,60\% de metionina + cistina, $0,90 \%$ de cálcio e $0,30 \%$ de fósforo disponível. A ração foi fornecida ad libitum durante todo o período de criação. $\mathrm{O}$ produto pro- 
biótico utilizado tinha como princípio ativo bactérias do gênero Enterococcus ssp $\left(10^{6} \mathrm{UFC} / \mathrm{g}\right)$ e bactérias do gênero Lactobacillus acidophilus ( $\left.10^{7} \mathrm{UFC} / \mathrm{g}\right)$, comercializado sob o nome Colostrum Mix pela empresa BioCamp Laboratórios Ltda, Campinas-SP.

Foram utilizados 1050 pintos de um dia, machos da linhagem comercial Ross 308 criados até 42 dias de idade. Os pintinhos foram vacinados, contra a Doença de Marek, Gumboro e Coccidiose. A cama de maravalha era nova quando utilizada no experimento. A limpeza dos bebedouros foi realizada diariamente, bem como o manejo das cortinas.

Foi utilizado um delineamento inteiramente casualizado com seis tratamentos e cinco repetições por tratamento. Foram utilizados 1050 frangos machos da linhagem Ross 308 totalizando trinta e cinco aves por boxe. Para os tratamentos foram empregados diferentes níveis de nucleotídeos $(0 ; 100 ; 200 ; 300 ; 400$ e 500 gramas por tonelada de ração), sendo que estes foram utilizados na fase inicial ( 1 a 21 dias) e de crescimento (22 a 35 dias), sendo retirados na fase final (36 a 42 dias). O grupo controle era composto apenas pela dieta basal contendo probiótico como alternativa aos antibióticos promotores de crescimento. A apresentação dos nucleotídeos utilizados era a de um produto em pó na concentração de $90 \%$ de nucleotídeo e $10 \%$ de sódio.

O peso das aves e o consumo de ração foram quantificados em cada fase de criação, ou seja, aos 21; 35 e 42 dias de idade. Também foram determinados: peso médio (PM), ganho de peso médio (GPM), consumo de ração (CR), conversão alimentar (CA), e índice de eficiência produtiva (IEP). O ácido úrico (AU) foi analisado no sangue coletado aos 21 e 35 dias.

Os resultados foram analisados com o auxílio do programa estatístico Statistical Analysis System ${ }^{6}$. Os dados foram submetidos à análise de variância pelo procedimento GLM. As características determinadas foram utilizadas como variáveis dependentes na determinação das equações de regressão. Para estimar os níveis de nucleotídeos utilizaram-se os modelos quadráticos, obtidos para cada variável dependente.

$\mathrm{Y}_{\mathrm{ij}}=\mu+\mathrm{A}_{\mathrm{i}}+\mathrm{e}_{\mathrm{ij}}$, sendo:

$\mathrm{Y}_{\mathrm{ijk}}=$ variáveis dependentes estudadas no desempenho;

$\mu=$ média geral da variável

$\mathrm{A}_{\mathrm{i}}=$ efeito do nível de nucleotídeo $\mathrm{i}$, sendo $\mathrm{i}=0 ; 100$ $200 ; 300 ; 400 ; 500 \mathrm{~g} / \mathrm{T}$.

$\mathrm{E}_{\mathrm{ij}}=$ erro aleatório associado a cada observação

\section{Resultados e Discussão}

Os resultados de desempenho dos frangos dos 1 a 21 de idade estão apresentados na tabela 1. Das variáveis avaliadas o Ganho de Peso Médio (GP), foi influenciado pelo nível de nucleotídeos. De 1 a 21 dias de idade constatando-se aumento linear no ganho de peso quando aumentou a quantidade de nucleotídeo $(\mathrm{P}<0,05)$ na ração. $\mathrm{O}$ peso vivo $(\mathrm{PM})$ aos 21 dias também apresentou efeito linear $(\mathrm{P}<0,05)$ conforme aumentou o nível de nucleotídeo na ração.

Os resultados obtidos diferem dos de $\mathrm{Garcia}^{7}$, que não detectou nenhum efeito significativo para ganho de peso (GP), tampouco para consumo de ração diário em suínos alimentados com dietas suplementadas com nucleotídeos, durante o período de 1 a 14 dias e 1 a 33 dias de experimento. Já Yu et al. ${ }^{8}$ relataram que leitões recém-desmamados apresentaram maior ganho de peso, quando alimentados com nucleotídeos e glutamina, comparados ao controle sem os produtos.

No presente experimento, as aves alimentadas com rações contendo nucleotídeos nos diferentes níveis empregados não apresentaram alteração no consumo de ração. Todavia, os dados obtidos por Rutz et al. ${ }^{9}$ são diferentes dos obtidos neste trabalho, pois estes autores observaram maior consumo de alimento até 31 dias de idade, em frangos alimentados com extrato de levedura como fonte de nucleotídeo. Do mesmo modo, o consumo maior de alimentos foi observado por Tibbetts ${ }^{1}$ e Maribo ${ }^{10}$ quando utilizaram extrato de levedura como fonte de nucleotídeos. 
Tabela 1 - Médias de ganho de peso (GP), peso médio das aves (PM), conversão alimentar (CA), consumo de ração (CR), e nível sanguíneo de acido úrico (AU) de frangos de corte no período de 1 a 21 dias em função do nível de nucleotídeos

\begin{tabular}{|c|c|c|c|c|c|c|c|c|c|}
\hline \multirow{2}{*}{$\begin{array}{l}\text { Parâmetros } \\
\text { Avaliados }\end{array}$} & \multicolumn{6}{|c|}{ Níveis de Nucleotídeos } & \multirow{2}{*}{$\frac{\mathrm{CV}}{\%}$} & \multicolumn{2}{|c|}{ Efeito } \\
\hline & 0 & 100 & 200 & 300 & 400 & 500 & & $\mathrm{~L}$ & Q \\
\hline GP (g) & $955,00 \pm 46,3^{\mathrm{a}}$ & $837,06 \pm 43,0^{c}$ & $954,65 \pm 49,1^{\mathrm{a}}$ & $947,57 \pm 48,7^{\mathrm{b}}$ & $958,48 \pm 49,3^{\mathrm{a}}$ & $944,91 \pm 48,6^{\mathrm{b}}$ & 5,14 & 0,0008 & 0,2887 \\
\hline PM (g) & $999,40 \pm 22,0^{\mathrm{a}}$ & $881,40 \pm 19,4^{\mathrm{b}}$ & $999,20 \pm 22,0^{\mathrm{a}}$ & $992,40 \pm 21,8^{\mathrm{a}}$ & $1003,40 \pm 22,1^{\mathrm{a}}$ & $989,40 \pm 21,8^{\mathrm{a}}$ & 2,179 & 0,0007 & 0,2985 \\
\hline $\mathrm{CA}$ & $1,392 \pm 0,07^{\mathrm{a}}$ & $1,554 \pm 0,07^{\mathrm{b}}$ & $1,368 \pm 0,06^{c}$ & $1,396 \pm 0,07^{\mathrm{a}}$ & $1,398 \pm 0,07^{\mathrm{a}}$ & $1,410 \pm 0,07^{\mathrm{a}}$ & 4,81 & 0,0053 & 0,9874 \\
\hline CR (g) & $1329,48 \pm 27,8^{\mathrm{a}}$ & $1301,19 \pm 26,0^{\mathrm{a}}$ & $1305,69 \pm 26,1^{a}$ & $1323,86 \pm 26,5^{\mathrm{a}}$ & $1338,28 \pm 26,8^{\mathrm{a}}$ & $1333,71 \pm 26,7^{\mathrm{a}}$ & 2,06 & 0,1519 & 0,1683 \\
\hline $\mathrm{AU}(\mathrm{mg} / \mathrm{dL})$ & $0,2404 \pm 0,05^{\mathrm{a}}$ & $0,1756 \pm 0,04^{c}$ & $0,2070 \pm 0,05^{\mathrm{b}}$ & $0,1832 \pm 0,04^{c}$ & $0,2208 \pm 0,05^{\mathrm{b}}$ & $0,2492 \pm 0,06^{\mathrm{a}}$ & 22,78 & 0,3987 & 0,0210 \\
\hline
\end{tabular}

a,b,c,d Letras diferentes na mesma linha indicam diferenças significativas $(P<0,05)$ entre os níveis de Nucleotídeos L - Probabilidade de Efeito Linear

Q - Probabilidade de Efeito Quadrático

Até os 21 dias de idade, observou-se um efeito linear na conversão alimentar (CA), apresentando melhora significativa e este parâmetro numericamente foi melhor quando se utilizou $200 \mathrm{~g}$ de nucleotídeo / T de ração. No estudo de Garcia ${ }^{7}$, não se observou nenhum efeito significativo na conversão alimentar, em suínos alimentados com dietas com nucleotídeo durante o período de 1 a 14 dias de idade, entretanto houve melhora numérica desta variável quando foram utilizados 4.000 ppm de nucleotídeo em relação a outros níveis utilizados na dieta.

Do mesmo modo, Rutz et al. ${ }^{9}$ obtiveram melhora na conversão alimentar de 1 a 7 dias de idade e de 38 a 42 dias de idade, em frangos alimentados com extrato de leveduras tendo como fonte nucleotídeos. Neste experimento, houve uma melhora de desempenho representada um efeito linear no peso e ganho de peso médio, e uma melhora para a conversão alimentar entre 1 a 21 dias de idade, conforme o aumento do nível de nucleotídeos na dieta.

Aos 21 dias de idade, conforme verifica-se na figura 1, observou-se efeito quadrático para os níveis de ácido úrico no sangue das aves, onde o valor de 231,59g/T de nucleotídeo, foi a concentração respon- $y=0,0000009 x^{2}-0,0004 x+0,231 R^{2}=0,2049$

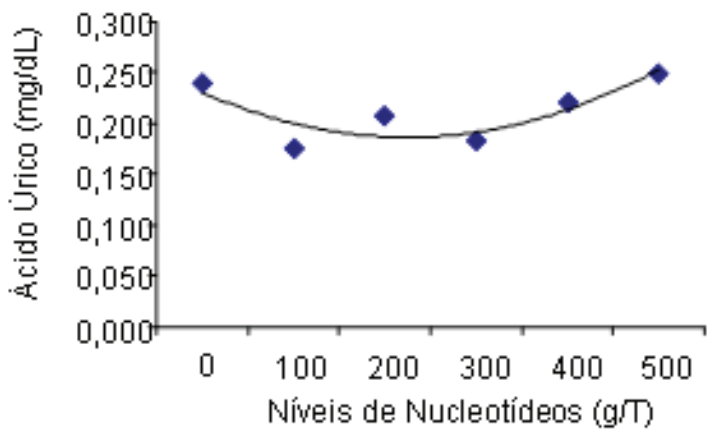

Figura 1 - Dosagem de ácido Úrico no sangue dos frangos de corte, no período de 21 dias de idade, conforme níveis de nucleotídeos na dieta

sável pela menor dosagem de ácido úrico no sangue dos frangos aos 21 dias de idade.

Para os resultados de desempenho aos 35 dias de idade, também se observou efeito linear $(\mathrm{P}<0,05)$ para o peso das aves (Tabela 2); o consumo de ração teve um aumento conforme os níveis de nucleotídeos adicionados na dieta, onde o nível de $400 \mathrm{~g}$ de nucleotídeo e $2.366,93 \mathrm{~g}$ de peso foi numericamente melhor. O peso das aves de 22 a 35 dias se apresentou de modo linear significativo à quantidade de nucleotídeos adicionados à dieta. Aos 35 dias, os níveis de ácido úrico 
Tabela 2 - Médias de ganho de peso (GP), peso médio das aves (PM), conversão alimentar (CA), consumo de ração (CR), e nível sanguíneo de acido úrico (AU) de frangos de corte no período de 22 a 35 dias de idade em função do nível de nucleotídeos

\begin{tabular}{|c|c|c|c|c|c|c|c|c|c|}
\hline \multirow{2}{*}{$\begin{array}{l}\text { Parâmetros } \\
\text { Avaliados }\end{array}$} & \multicolumn{6}{|c|}{$\begin{array}{l}\text { Níveis de Nucleotídeos } \\
(\mathrm{g})\end{array}$} & \multirow{2}{*}{$\frac{\mathrm{CV}}{\%}$} & \multicolumn{2}{|c|}{ Efeito } \\
\hline & 0 & 100 & 200 & 300 & 400 & 500 & & $\mathrm{~L}$ & Q \\
\hline GP (g) & $1321,00 \pm 33,0^{\mathrm{a}}$ & $1352,33 \pm 33,8^{\mathrm{a}}$ & $1321,27 \pm 33,0^{\mathrm{a}}$ & $1311,92 \pm 32,8^{\mathrm{a}}$ & $1363,53 \pm 34,1^{\mathrm{a}}$ & $1346,60 \pm 33,7^{a}$ & 2,540 & 0,2175 & 0,5007 \\
\hline PM (g) & $2324,50 \pm 39,5^{a}$ & $2233,73 \pm 38,0^{b}$ & $2320,47 \pm 39,4^{\mathrm{a}}$ & $2304,32 \pm 39,2^{c}$ & $2366,93 \pm 40,2^{d}$ & $2336,00 \pm 39,7^{b}$ & 1,677 & 0,0079 & 0,2314 \\
\hline $\mathrm{CA}$ & $1,815 \pm 0,05^{\mathrm{a}}$ & $1,742 \pm 0,05^{\mathrm{a}}$ & $1,834 \pm 0,05^{\mathrm{a}}$ & $1,826 \pm 0,05^{\mathrm{a}}$ & $1,790 \pm 0,05^{\mathrm{a}}$ & $1,820 \pm 0,05^{\mathrm{a}}$ & 2,660 & 0,6533 & 0,6131 \\
\hline CR (g) & $2395,87 \pm 43,1^{\mathrm{a}}$ & $2354,92 \pm 42,4^{\mathrm{b}}$ & $2423,90 \pm 43,6^{c}$ & $2396,63 \pm 43,1^{a}$ & $2438,19 \pm 43,9^{c}$ & $2426,07 \pm 43,7^{c}$ & 1,839 & 0,4791 & 0,8349 \\
\hline $\mathrm{AU}(\mathrm{mg} / \mathrm{dL})$ & $0,1598 \pm 0,04^{c}$ & $0,1434 \pm 0,03^{c}$ & $0,1040 \pm 0,02^{\mathrm{a}}$ & $0,1374 \pm 0,03^{\mathrm{c}}$ & $0,1612 \pm 0,04^{\mathrm{c}}$ & $0,1914 \pm 0,04^{\mathrm{b}}$ & 24,588 & 0,0921 & 0,0049 \\
\hline
\end{tabular}

a,b,c,d Letras diferentes na mesma linha indicam diferenças significativas $(\mathrm{P}<0,05)$ entre os níveis de Nucleotídeos

L - Probabilidade de Efeito Linear

Q - Probabilidade de Efeito Quadrático

no sangue se apresentaram de forma quadrática onde o valor de 208,99g é a quantidade de nucleotídeo significativa para a dosagem de ácido úrico no sangue dos frangos (Figura 2).

Os dados referentes aos períodos de 36 a 42 e de 1 a 42 dias de idade, apresentados nas tabelas 3 e 4, não demonstraram nenhum efeito significativo no desempenho de frangos de corte alimentados com dieta suplementada com nucleotídeos de 0 até $500 \mathrm{~g} / \mathrm{T}$. de ração. Do mesmo modo Pelícia et al. ${ }^{11}$ relataram que níveis crescentes de nucleotídeos na dieta de frangos de corte, sem desafio sanitário, não apresentaram ne-

$$
y=0,0000008 x^{2}-0,0004 x+0,1609 R^{2}=0,3262
$$

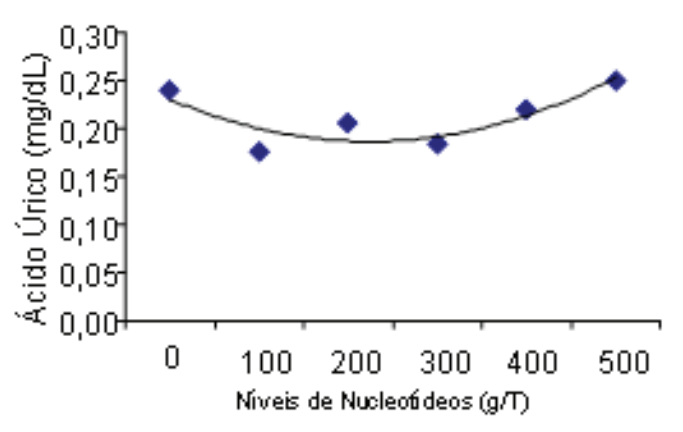

Figura 2 - Dosagem de ácido úrico no sangue de frangos de corte, aos 35 dias de idade. nhum efeito da suplementação no desempenho das aves aos 7, 21 e 42 dias de idade.

No presente experimento, as boas práticas de manejo, a ausência de desafio sanitário e a utilização do produto probiótico podem ter sido determinantes para a ausência de efeitos mais expressivos dos nucleotídeos testados sobre o desempenho das aves. Menten e Pedroso ${ }^{12}$ relatam que é necessário um desafio sanitário de campo, para que os aditivos promotores de crescimento produzam efeitos significativos sobre o desempenho de aves e suínos; estes aditivos poderiam apresentar respostas superiores às encontradas experimentalmente. Zavarize ${ }^{13}$ também observou que não houve interação entre os níveis de inclusão de glutamina e nucleotídeos em variáveis de desempenho aos 7, 21 e 42 dias de idade em frangos de corte.

Nunes et al. ${ }^{14}$ confirmaram que a adição de extrato de levedura em níveis crescentes (1\%, 2\%, e 3\%) em dietas de poedeiras comerciais, não provocou efeito significativo sobre o desempenho produtivo das aves. Do mesmo modo, Zauk et al. ${ }^{15}$ e Santos et al. ${ }^{16}$ não constataram diferença significativa em níveis de $0 \%$ a $15 \%$ de extrato de levedura na dieta de frangos de corte. 
Tabela 3 - Médias de ganho de peso (GP), conversão alimentar (CA) e consumo de ração (CR) de frangos de corte no período de 36 a 42 dias em função do nível de nucleotídeos

\begin{tabular}{|c|c|c|c|c|c|c|c|c|c|}
\hline \multirow{2}{*}{$\begin{array}{l}\text { Parâmetros } \\
\text { Avaliados }\end{array}$} & \multicolumn{6}{|c|}{$\begin{array}{l}\text { Níveis de Nucleotídeos } \\
\text { (g) }\end{array}$} & \multirow{2}{*}{$\begin{array}{c}\mathrm{CV} \\
\%\end{array}$} & \multicolumn{2}{|c|}{ Efeito } \\
\hline & 0 & 100 & 200 & 300 & 400 & 500 & & $\mathrm{~L}$ & Q \\
\hline GP (g) & $765,40 \pm 68,9$ & $823,66 \pm 74,1$ & $814,13 \pm 73,27$ & $774,88 \pm 69,7$ & $717,08 \pm 64,5$ & $796,99 \pm 71,7$ & 8,93 & 0,4606 & 0,7717 \\
\hline CA & $2,059 \pm 0,20$ & $1,988 \pm 0,20$ & $1,968 \pm 0,20$ & $2,040 \pm 0,20$ & $2,014 \pm 0,20$ & $1,966 \pm 0,20$ & 10,58 & 0,6891 & 0,9126 \\
\hline CR (g) & $1405,68 \pm 98,4$ & $1495,74 \pm 104,7$ & $1443,67 \pm 101,0$ & $1427,97 \pm 99,9$ & $1356,41 \pm 94,9$ & $1422,90 \pm 99,6$ & 6,61 & 0,6048 & 0,6755 \\
\hline
\end{tabular}

L - Probabilidade de Efeito Linear

Q - Probabilidade de Efeito Quadrático

Tabela 4 - Médias de ganho de peso (GP), peso médio das aves (PM), conversão alimentar (CA), consumo de ração (CR), índice de eficiência produtiva (IEP) de frangos de corte no período de 01 a 42 dias em função do nível de nucleotídeos

\begin{tabular}{lccccccccc}
\hline & \multicolumn{7}{c}{ Níveis de Nucleotídeos } \\
Parâmetros \\
Avaliados
\end{tabular}

L - Probabilidade de Efeito Linear

Q - Probabilidade de Efeito Quadrático

\section{Conclusão}

Com base nos resultados obtidos neste estudo, conclui-se que no período de 1 a 21 dias de idade, com o aumento do nível de inclusão de nucleotídeos na dieta, houve melhora na conversão alimentar, peso médio e ganho de peso das aves. No entanto o resultado positivo da inclusão de nucleotídeos na dieta não foi observado nos períodos posteriores, recomendando-se mais estudos para o presente assunto. 


\section{Referências}

1.TIBBETTS, G. W. Nucleotides from yeast extract: potential to replace animal protein sources in food animal diets. In: ANNUAL SYMPOSIUM OF NUTRITIONAL BIOTECHNOLOGY IN THE FEED AND FOOD INDUSTRIES, 18., 2002, Nottinghan. Proceedings... Nottinghan: University Press, 2002. p. 435-443.

2.DAWSON, K. A.; PIRVULESCU, M. Mananoligossacarídeos derivados de leveduras como moduladores da resposta imunológica e alternativas aos promotores de crescimento antimicrobianos. In: RONDA LATINO AMERICANA DA ALLTECH, 9., 1999, Curitiba, Paraná. Anais... Curitiba: Alltech, 1999. p. 33-41.

3. CRUZ, V. C.; PELÍCIA, V. C.; SARTORI, J. R.; ZAVARIZE, K. C.; CAZERTA, S. M. Efeitos da adição de nucleotídeos na dieta sobre o perfil bioquímico sanguíneo de frangos de corte alternativos. In: SIMPOSIO DE CIÊNCIAS DA UNESP, 4.; ENCONTRO DE ZOOTECNIA UNESP, 5., 2008, Dracena. Anais...2008. p. 36-45.

4. MATEO, C. D.; DAVE, R. I.; STEIN, H. H. Effect of supplemental nucleosides for newly weaned pigs. Journal of Animal Science, v. 2, p. 21, 2004. Supplement,2.

5. UAUY, R.; QUAN, R.; GIL, A. Role of nucleottides in intestinal development and repair: implications for infant nutrition, Journal of Nutrition, v. 124, n. 8, p. 1436- 1441, 1994.

6. STATISTICAL ANALISYS SYSTEM. Institute Incorporation. SAS User's guide: statistics. 5. ed. Cary: SAS, 1999.

7. GARCIA, A. N. Nucleotídeos como potenciais promotores de crescimento de leitões recém-desmamados. 2007. 40 p. Dissertação (Mestrado) - Escola Superior de Agricultura Luis de Queiroz, Universidade de São Paulo, Piracicaba, 2007.

8. YU, I. T.; WU, J. F.; YANG, P. C.; LIU, C. Y.; LEE, D. N.; YEN, H. T. Roles of glutamine and nucleotides in combination in growth, immune responses and FMD antibody titres of weaned pigs. Animal Science, v. 75, p. 379-385, 2002.

9. RUTZ, F.; ANCIUTI, M. A.; RECH, J. L.; GONÇALVES, F. M.; DELGADO, A. D.; ROSA, E. R.; ZAUK, N.; RIBEIRO, C. L. G.; SILVA. R. R.; DALMANN. P. R. Desempenho e características de carcaça de frangos de corte recebendo alimentação de extrato de leveduras na dieta. Ciência Animal Brasileira, v. 7, n. 4, p. 349-355, 2006.

10.MARIBO, H. Weaning pigs without antibiotic growth promoters: strategies to improve health and performance. In: NUTRITIONAL BIOTECHNOLOGY IN THE FEED AND FOOD INDUSTRIES, 19., 2003, Lexington. Anais... Lexington: Nottinghan University Press, 2003. v. 1, p. 179-184.

11.PELÍCIA, V. C.; SARTORI, J. R.; ZAVARIZE, K. C.; MITUO, M. A. O.; PEZZATO, A. C.; MARTINS, B. A. B. Níveis de nucleotídeos na ração de frangos de corte como alternativa ao uso de antibióticos promotores de crescimento. In: Conferência APINCO de Ciência e Tecnologia Avícola, 2007, Santos-SP. Revista Brasileira de Ciência Avícola, v. 7, p. 5454, 2007. Suplemento, 9.

12. MENTEN, J. F. M.; PEDROSO, A. A. Fatores que interferem na eficácia de probióticos. In: CONFERÊNCIA APINCO DE CIÊNCIA E TECNOLOGIA AVICOLAS, 2005, Santos, São Paulo. Anais... Campinas: FACTA, 2005. v. 1, p. 41-52.

13.ZAVARIZE, K. C. Glutamina e nucleotídeos na dieta de frangos de corte criados no sistema alternativo. Botucatu, 200840 f. Dissertação (Mestrado) - Faculdade de Medicina Veterinária e Zootecnia, Universidade Estadual Paulista, Botucatu - SP., 2008.

14.NUNES, J. K.; MAIER, J. C.; ROSSI, P.; DALLMANN, P. R.; ANCIUTI, M. A.; RUTZ, F.; SILVA, J. G. C. Suplementação de extrato de levedura na dieta de poedeiras comerciais: desempenho produtivo. Revista Ciência Animal Brasileira, v. 9, n. 2, p. 357-364, 2008.

15.ZAUK, N. H. F.; LOPES, D. C. M.; SILVA, L. M.; DALLMANN, P. R.; RIBEIRO, C. L. G.; PINTO, J. R. A. O.; MIELKE, R. B.; ANCIUTI, M. A.; RUTZ, F. Performance and carcass traits of broilers fed pre-starter diets containing Nupro. In: NUTRITIONAL BIOTECHNOLOGY IN THE FEED AND FOOD INDUSTRIES, 22., 2006, Lexington. Proceedings... Alltech, 2006. p. 10.

16.SANTOS, JR., A. A.; BOHORQUEZ, D. V.; NANNEY, R. L.; FERKET, P. R. Nutrient digestibility value of yeast extract, Nupro, In. Male broiler chicks.In: NUTRITIONAL BIOTECHNOLOGY IN FEED AND FOOD INDUSTRIES, 23. 2007, Lexington. Proceedings...Lexington: Alltech, 2007. p. 19. 